\title{
Produção de lentes orgânicas no Pólo Industrial de Manaus
}

\section{Time and motion study applied to a production line of organic lenses in Manaus Industrial Hub}

GESTÃO

PRODỰ̂̃O

ISSN 0104-530X (Print) ISSN 1806-9649 (Online)

\author{
Pedro Henrique Araújo Cury ${ }^{1}$ \\ José Saraiva ${ }^{1}$
}

\begin{abstract}
Resumo: Este artigo apresenta um estudo de caso sobre a utilização da técnica de tempos e métodos aplicado em uma linha de produção de lentes orgânicas de uma empresa multinacional, localizada no Pólo Industrial de Manaus, Amazonas. O objetivo deste artigo é viabilizar a inserção de pausas de cinco minutos a cada uma hora de produção, mantendo a produtividade sem alterar a demanda ou aumentando a carga horária dos operadores. De forma específica, utilizou-se as principais técnicas de tempos e métodos para otimizar as operações, identificando atividades agregadoras ou não de valor, além de desperdícios. O estudo de caso descreve a situação em que se encontra a organização, a situação proposta, o tratamento de dados e os resultados obtidos.
\end{abstract}

Palavras-chave: Tempos e métodos; Lentes orgânicas; Otimizar operações; Desperdícios.

Abstract: This article presents a case study about the utilization of the time and motion technique applied to a production line of organic lenses in a multinational company, located in Manaus Industrial Hub (PIM), Amazonas. This article's goal is to allow the insertion of five-minute breaks for each production hour, maintaining productivity without changing the demand or increasing operators'workload. In a specific way, the main time and motion techniques were utilized in order to optimize operations, identifying value-added and non-value-added activities, and wastes. The case study describes the company's current scenario, proposed situation, the data treatment and the results.

Keywords: Time and motion study; Organic lenses; Operation optimization; Wastes.

\section{Introdução}

A competitividade do mercado desenvolve uma busca contínua pela melhoria de processos, produtos e serviços em todas as organizações. Caso uma empresa não se concentre em reduzir os custos e garantir a qualidade daquilo que oferece, compromete sua sobrevivência no mercado. Nesse contexto, destaca-se o conceito de produção enxuta e suas ferramentas, que visam diminuir todos os tipos de desperdício dentro de uma empresa.

A produção enxuta surgiu dentro do Sistema Toyota ${ }^{\circledR}$ de Produção com o objetivo de tentar eliminar os sete desperdícios: superprodução, espera, transporte, processamento incorreto, estoque, movimentação e defeitos. Por meio dessa filosofia, as empresas começaram a classificar operações em agregadoras ou não agregadoras de valor, procurando sempre otimizar seus processos. Para isso desenvolveu-se ferramentas de auxílio como o estudo de tempos e métodos. Este artigo dedica-se a aplicação do estudo de tempos e métodos, por meio de cronoanálises e classificação de tarefas em valor agregado, não agregado e desperdício em uma linha de lentes orgânicas de uma fábrica multinacional francesa localizada no Pólo Industrial de Manaus, Amazonas.

O presente estudo é composto por introdução, fundamentação teórica, metodologia, estudo de caso e considerações finais. Dando ênfase a demonstração dos resultados do estudo de caso após a aplicação do estudo de tempos e métodos, mostrando um comparativo entre a situação anterior e a futura, afim de mostrar a eficácia da metodologia estudada.

\section{Referencial teórico}

\subsection{Produção enxuta e os sete desperdícios}

A Produção enxuta surgiu no Japão após a segunda guerra mundial. Nesse período, a Toyota Motor Company ${ }^{\circledR}$ enfrentava desafios desanimadores em termos financeiros, tecnológicos e relações trabalhistas assim como outras diversas organizações

\footnotetext{
${ }^{1}$ Universidade Federal do Amazonas - UFAM, Av. General Rodrigo Octavio Jordão Ramos, 1200, Coroado I, CEP 69067-005, Manaus, AM, Brasil, e-mail: curyped@gmail.com; inovex@outlook.com
} 
japonesas. Eiji Toyoda e o engenheiro Taiichi Ohno chegaram à conclusão de que a produção em massa não serviria para o Japão naquela atual conjuntura. Portanto, criaram um sistema que se fazia necessário. Segundo Werkema (2012), o Lean Manufacturing é uma iniciativa que procura eliminar desperdícios, excluindo o que não agrega valor para o cliente e transmitindo velocidade às organizações.

A competitividade do mercado torna o preço uma variável controlada pelos consumidores. O consumidor, mais poderoso do que nunca, tem uma enorme variedade de escolhas, acesso sem precedentes a informação e está exigindo excelente qualidade à um preço razoável. Assim, as empresas necessitam descobrir novos meios de reduzir seus custos para poder maximizar seu lucro. Para isso o STP, como principal virtude, promove o ataque intenso aos desperdícios dos processos. Incentivando sempre o envolvimento dos seus funcionários nos processos de melhoria.

Segundo os princípios da produção enxuta, há três tipos de trabalho que podem ser identificados nos processos de produção ou prestação de serviços:

a) Valor agregado - É todo trabalho que modifica o produto, em outras palavras, é um trabalho pelo qual o cliente final está disposto a pagar;

b) Valor não agregado - É o trabalho que não modifica o produto, o cliente não paga por ele, mas são necessários para fabricação e garantia da qualidade do mesmo. Deve ser minimizado;

c) Desperdício -É o trabalho que não agrega valor ao produto, pois o cliente não paga por ele, e não é necessário para sua fabricação e/ou garantia da qualidade. Deve ser sempre evitado.

De acordo com Mayer et al. (2015, p. 180),

O trabalho pode ser dividido em trabalho que agrega valor e que não agrega valor. $\mathrm{O}$ trabalho que não agrega valor pode ser considerado como desperdício. Já aquele que agrega valor é o que envolve processamento para mudar ou transformar um produto ou a montagem do mesmo. Deve-se considerar também que o trabalho que não agrega valor pode ser considerado necessário, devido às características de máquinas e processos.

Ainda segundo Mayer et al. (2015), os desperdícios são caracterizados por todos os elementos da produção que não agregam valor ao produto final, aumentando os custos, sendo os mesmos repetitivos e desnecessários, devendo ser eliminados.

A Toyota ${ }^{\circledR}$ identificou os sete tipos principais de atividades sem valor agregado em processos empresariais ou de manufatura, os quais serão descritos abaixo. São aplicáveis não só na linha de produção como também ao desenvolvimento de novos produtos, a tomada de pedidos e decisões, e ao escritório:

a) Superprodução - Produzir itens mais cedo ou em maiores quantidades do que o cliente necessita. Produzir antes ou mais do que é necessário gera outras perdas, tais como custos com excesso de pessoal, armazenagem e transporte devido ao estoque excessivo. $\mathrm{O}$ estoque pode ser físico ou um conjunto de informações;

b) Espera - Trabalhadores servindo meramente como vigias de uma máquina automatizada ou tendo que ficar esperando pela próxima etapa do processamento ou ferramenta, suprimento, peça, etc. Ou, ainda, simplesmente não tendo trabalho por falta de estoque, atrasos de processamento, paralisação do equipamento e gargalos de capacidade;

c) Transporte ou transferência - Movimentação de trabalho em processo de um local para outro, mesmo se for em uma curta distância. Movimentação de materiais, peças ou produtos acabados para estocá-los ou retirá-los do estoque entre processos;

d) Processamento incorreto - Realização de atividades ou tarefas desnecessárias para processar as peças. Processamento ineficiente devido a má qualidade das ferramentas e do projeto do produto, causando defeitos ou deslocamentos desnecessários;

e) Excesso de estoque - Excesso de matéria-prima, estoque em processo ou produtos acabados, causando lead times mais longos, obsolescência, produtos danificados, custos com transporte, armazenagem e atrasos. Além disso, o estoque extra oculta problemas, tais como desequilíbrios na produção, entregas com atraso por parte dos fornecedores, defeitos, paralização de equipamentos e longos setups;

f) Deslocamentos desnecessários - Qualquer movimento que os funcionários têm que fazer durante seu período de trabalho que não seja para agregar valor a peça, tais como localizar, procurar ou empilhar peças, ferramentas, etc. Além disso, caminhar também é perda;

g) Defeitos - Produção ou correção de peças defeituosas. Conserto ou retrabalho, descarte, produção para substituição e inspeção significam desperdício de tempo, de manuseio e esforço. 
Houts (2016) enfatiza que os desperdícios são tradicionalmente classificados em sete: superprodução, espera, transporte, processamento incorreto, excesso de estoque, movimentação e defeitos.

A superprodução é considerada o pior dos sete desperdícios, pois ocasiona a maioria dos outros tipos de perda. Afinal, produzir antes ou produzir mais que a quantidade necessária leva a formação de estoque em algum ponto posterior no processo e/ou o material fica aguardando para ser processado na operação seguinte. Conforme Houts (2016), além dos sete desperdícios, pode ser adicionado um oitavo: pessoas subutilizadas - que são recursos que tem o seu tempo gasto com processos ineficientes ou tempo de espera desnecessários.

\subsection{Padronização do trabalho, tempo de ciclo e takt time}

A padronização do trabalho é a maneira mais segura, fácil e eficaz de se realizar uma tarefa. Trata-se de criar um meio para ter o desempenho mais consistente possível. Para Werkema (2011), a padronização é uma ferramenta muito importante na redução da variabilidade de um processo, pois tarefas e procedimentos executados de forma padronizada por todos operadores em uma empresa reduz a chance de haver erro nesta tarefa e/ou procedimento.

As principais ferramentas no estabelecimento de processos e procedimentos padronizados são os documentos de padrão de trabalho e técnicas de produção enxuta. Os documentos de padrão das operações ajudam a manter o processo consistente, controlar o processo e evitar variações. As técnicas de produção enxuta permitem que se crie uma base de avaliação das tarefas e, assim, identificar oportunidades de melhorias e a evitar erros no processo. Além dessas características, o padrão de trabalho tem outros benefícios:

1. Pontos de início e paradas no processo - Permite determinar a condição da produção com facilidade;

2. Aprendizagem organizacional $-\mathrm{O}$ trabalho padronizado mantém o know-how e a experiência, quando um operador experiente sai, seu conhecimento não é perdido;

3. Treinamento $-\mathrm{O}$ trabalho padronizado fornece uma base para o treinamento de funcionários.

Segundo Marksberry et al. (2011), o trabalho padronizado não é somente uma ferramenta de documentação ou treinamento, mas sim uma ferramenta de análise de trabalho.

O takt time é fundamental para padronizar um trabalho, afinal ele diz com que frequência deve haver uma saída de produto na linha. Conforme
Sabet-Rasekh (2014), o takt time é o ritmo de produção de um processo. De acordo com Wang et al. (2014), o takt time é uma função que determina quão rápido deve ser um processo para atingir a demanda do cliente. Em termos de cálculo, é o tempo disponível para produzir peças em um intervalo específico de tempo dividido pelo número de peças demandadas naquele intervalo. Para Sabet-Rasekh (2014) o takt time é comumente associado ao tempo de ciclo, enquanto o primeiro é baseado na necessidade do cliente, o segundo representa a capacidade de produção daquele processo.

Geralmente, utiliza-se um gráfico de equilíbrio de operação para mostrar como os tempos de ciclo se comparam com o tempo de takt. Pode-se ser utilizado para retirar dúvidas sobre a capacidade do processo. Caso os tempos de ciclo das operações não apresentem grandes variações, significa que as atividades das linhas estão bem balanceadas e padronizadas.

\subsection{Estudo de tempos e métodos}

O estudo de tempos e métodos proporciona técnicas para analisar detalhadamente uma operação ou tarefa, medindo quais atividades agregam valor e como minimizar e eliminar as que não agregam ou que são consideradas desperdício. Por meio do estudo de tempos e métodos de um processo produtivo, é possível calcular sua capacidade e aumentar sua eficiência e produtividade, tornando a organização mais competitiva a ponto de ter custos de produção mais baixos, oferecer um produto de qualidade e de menor preço ao consumidor.

Utilizando o estudo de tempos e métodos, desenvolve-se um melhor modo de realizar as operações de um processo. Atribui-se movimentos e um tempo padrão para cada operação que deve ser seguido para que a organização encontre melhores resultados no mercado em que atua. De acordo com Souto (2002), a Engenharia de Métodos estuda e analisa o trabalho de forma sistemática, objetivando desenvolver métodos práticos e eficientes buscando a padronização do processo.

O tratamento de dados para o cálculo do tempo padrão segue 3 etapas:

1. Cálculo do número de amostragens - $\mathrm{O}$ número de amostragens ideal é calculado por uma equação, esta etapa será exemplificada na seção 4.2.1 deste artigo;

2. Os tempos cronometrados são multiplicados pelo fator de ritmo, o valor encontrado é chamado de tempo normal - $\mathrm{O}$ fator de ritmo é determinado pelo próprio cronometrista onde: 
V $>100 \%$ - Ritmo acima do normal;

$\mathrm{V}=100 \%$ - Ritmo normal;

$\mathrm{V}<100 \%$ - Ritmo abaixo do normal;

3. Os tempos normais encontrados são multiplicados pelo fator de tolerância de cada operação - $\mathrm{O}$ fator de tolerância é um valor correspondente a existência de uma tolerância por necessidades pessoais, fadiga, espera e o tempo de pausa.
Existem várias maneiras de calcular os fatores de ritmo e tolerância de uma atividade, para tornar a determinação menos subjetiva, utiliza-se o sistema de Westinghouse visto nas Tabelas 1 e 2 abaixo.

$\mathrm{O}$ sistema Westinghouse analisa quatro condições para determinar o fator de ritmo e de tolerância: habilidade, esforço, condições do ambiente e consistência. Assim, os fatores são diferentes para cada operação da linha de produção.

Tabela 1. Sistema de fator de ritmo Westinghouse.

\begin{tabular}{|c|c|c|c|c|c|}
\hline \multicolumn{3}{|c|}{ Habilidade } & \multicolumn{3}{|c|}{ Esforço } \\
\hline 0,15 & A1 & \multirow[t]{2}{*}{ Super-hábil } & 0,13 & A1 & \multirow[t]{2}{*}{ Excessivo } \\
\hline 0,13 & $\mathrm{~A} 2$ & & 0,12 & A2 & \\
\hline 0,11 & B1 & \multirow[t]{2}{*}{ Excelente } & 0,10 & B1 & \multirow[t]{2}{*}{ Excelente } \\
\hline 0,08 & B2 & & 0,08 & B2 & \\
\hline 0,06 & $\mathrm{C} 1$ & \multirow[t]{2}{*}{ Bom } & 0,05 & $\mathrm{C} 1$ & \multirow[t]{2}{*}{ Bom } \\
\hline 0,03 & $\mathrm{C} 2$ & & 0,02 & $\mathrm{C} 2$ & \\
\hline 0,00 & D1 & Médio & 0,00 & D1 & Médio \\
\hline$-0,05$ & E1 & \multirow[t]{2}{*}{ Regular } & $-0,04$ & E1 & \multirow[t]{2}{*}{ Regular } \\
\hline$-0,10$ & E2 & & $-0,08$ & E2 & \\
\hline$-0,16$ & $\mathrm{~F} 1$ & \multirow[t]{2}{*}{ Fraco } & $-0,12$ & $\mathrm{~F} 1$ & \multirow[t]{2}{*}{ Fraco } \\
\hline$-0,22$ & $\mathrm{~F} 2$ & & $-0,17$ & $\mathrm{~F} 2$ & \\
\hline \multicolumn{3}{|c|}{ Condições } & \multicolumn{3}{|c|}{ Consistência } \\
\hline 0,06 & $\mathrm{~A}$ & Ideal & 0,04 & $\mathrm{~A}$ & Perfeita \\
\hline 0,04 & B & Excelente & 0,03 & B & Excelente \\
\hline 0,02 & $\mathrm{C}$ & Bom & 0,01 & $\mathrm{C}$ & Bom \\
\hline 0,00 & $\mathrm{D}$ & Média & 0,00 & $\mathrm{D}$ & Média \\
\hline$-0,03$ & $\mathrm{E}$ & Regular & $-0,02$ & $\mathrm{E}$ & Regular \\
\hline$-0,07$ & $\mathrm{~F}$ & Básica & $-0,04$ & $\mathrm{~F}$ & Básica \\
\hline
\end{tabular}

Fonte: Adaptado de Barnes (1977).

Tabela 2. Sistema de fator de tolerância Westinghouse.

\begin{tabular}{|c|c|c|c|c|c|c|}
\hline & \multirow[b]{2}{*}{$\begin{array}{l}\text { Esforço } \\
\text { físico }\end{array}$} & \multirow[b]{2}{*}{ Esforço mental } & \multicolumn{2}{|c|}{ Recuperação } & \multicolumn{2}{|l|}{ Monotomia } \\
\hline & & & $\begin{array}{l}\% \text { Tempo } \\
\text { recuperado }\end{array}$ & Fator B & Duração do ciclo (min) & $\%$ \\
\hline \multirow{2}{*}{ Trabalho } & \multirow{2}{*}{$\%$} & \multirow{2}{*}{$\%$} & $0-5$ & 1 & \multirow{2}{*}{0 a 0,05} & 7,9 \\
\hline & & & $6-10$ & 0,9 & & \\
\hline \multirow{2}{*}{ Muito leve } & \multirow{2}{*}{1,8} & \multirow{2}{*}{0} & $11-15$ & 0,8 & \multirow{2}{*}{0,06 a 0,25} & 5,4 \\
\hline & & & $16-20$ & 0,71 & & \\
\hline \multirow{2}{*}{ Leve } & \multirow{2}{*}{3,6} & \multirow{2}{*}{0,6} & $21-25$ & 0,62 & \multirow{2}{*}{0,26 a 0,50} & 3,6 \\
\hline & & & $26-30$ & 0,54 & & \\
\hline \multirow{2}{*}{ Médio } & \multirow{2}{*}{5,4} & \multirow{2}{*}{1,8} & $31-35$ & 0,46 & \multirow{2}{*}{0,51 a 1,00} & 2,1 \\
\hline & & & $36-40$ & 0,39 & & \\
\hline \multirow{2}{*}{ Pesado } & \multirow{2}{*}{7,2} & \multirow{2}{*}{3} & $41-45$ & 0,32 & \multirow{2}{*}{1,01 a 2,00} & 1 \\
\hline & & & $46-50$ & 0,26 & & \\
\hline \multirow{2}{*}{ Muito Pesado } & \multirow{2}{*}{9} & \multirow{2}{*}{0} & $51-55$ & 0,2 & 2,01 a 3,00 & 0,5 \\
\hline & & & $56-60$ & 0,15 & 3,01 a 4,00 & 0,2 \\
\hline \multicolumn{7}{|c|}{ Condições ambientais } \\
\hline \multicolumn{2}{|c|}{ Térmicas } & \multicolumn{2}{|c|}{ Atmosféricas } & \multicolumn{3}{|c|}{ Outras } \\
\hline Temperatura & $\%$ & $\begin{array}{c}\text { Local } \\
\end{array}$ & $\%$ & \multicolumn{3}{|c|}{$\%$} \\
\hline 0 a $7{ }^{\circ} \mathrm{C}$ & 3,6 & Bem ventilado & 0 & \multirow{2}{*}{ Ruído } & Baixo nível & 0 \\
\hline 8 a $15^{\circ} \mathrm{C}$ & 1,8 & \multirow{2}{*}{$\begin{array}{l}\text { Mal ventilado ou com } \\
\text { leve fumaça }\end{array}$} & \multirow[b]{2}{*}{2,4} & & Obrigue uso de protetor & 1,8 \\
\hline 16 a $25^{\circ} \mathrm{C}$ & 0 & & & Umidade & $\begin{array}{l}\text { Ambiente seco e } \\
\text { agradável }\end{array}$ & 0 \\
\hline 26 a $34^{\circ} \mathrm{C}$ & 1,8 & Com muita fumaca ou nó & 56 & & Alta $\left(>25^{\circ} \mathrm{C}\right)$ & 1,8 \\
\hline 35 a $40^{\circ} \mathrm{C}$ & 3,6 & com muita rumaça ou po & 5,0 & Vibração & Do solo ou máquina & 1,8 \\
\hline
\end{tabular}




\subsection{Fluxograma de processo}

O fluxograma de processos é uma ferramenta de modelagem e simulação que tem como objetivo listar todas as fases de um processo produtivo, permitindo uma rápida visualização e entendimento, facilitando sua análise. Segundo Juran (1990), O fluxograma é a maneira mais eficaz de identificar os clientes, seguir o produto e ver o que é afetado por ele.

Para Paladini (2012), o fluxograma possibilita criar um entendimento comum, tornar claro os passos em um processo, identificar oportunidades de melhoria (complexidade, desperdício, atrasos, ineficiência e gargalos), revelar problemas no processo e revelar como este opera.

De acordo com Greef (2012), o fluxograma consiste em uma imagem momentânea da forma como a informação perpassa as funções do ambiente mapeado. Existem diversos tipos de símbolos empregados nos fluxogramas de processos, cada um com uma característica diferente que muda a maneira de analisar uma atividade, cabe ao profissional definir qual melhor se encaixa no processo a ser estudado.

\section{Metodologia}

\subsection{Ambiente estudado}

O estudo de caso a ser apresentado foi realizado em uma linha de montagem de lentes orgânicas de uma empresa multinacional francesa localizada na cidade de Manaus, Amazonas. A fábrica de Manaus é certificada pelas ISO 9000 e 14000 e é considerada a mais produtiva do mundo, com uma produção superior a 20 milhões de lentes por ano. O estudo em questão levou cerca de dois meses para ser realizado e contou com o apoio das equipes de engenharia de qualidade e processo.

\subsection{Caracterização da pesquisa}

A pesquisa trata-se de um estudo de caso como já fora afirmado na seção anterior. Para Gil (2010), o estudo de caso é caracterizado pelo estudo profundo e exaustivo de um ou de poucos objetos, de maneira a permitir conhecimentos amplos e detalhados do mesmo, tarefa praticamente impossível mediante outros tipos de delineamentos considerados. A pesquisa bibliográfica desenvolveu-se por meio de livros, artigos científicos, revistas e textos já publicados sobre o assunto em questão.

A abordagem da pesquisa é tanto qualitativa quanto quantitativa. Segundo Llewellyn \& Northcott (2007), a abordagem qualitativa centra-se na identificação das características de situações, eventos e organizações. Para Terence \& Escrivão-Filho (2006), pesquisa quantitativa possibilita ao pesquisador mensurar opiniões, hábitos, atitudes e reações por meio de uma amostra estatística que representa o universo pesquisado.

Quanto à natureza, é classificada como aplicada visto que tem finalidades imediatas, causando efeitos diretos ao processo. Aos objetivos, identifica-se como exploratória por possuir finalidade de obter mais conhecimento sobre um assunto e orientar objetivos e métodos. Como instrumento durante a pesquisa foram utilizados principalmente vídeos e entrevistas com pessoas responsáveis pelo processo estudado. A Tabela 3 representa um resumo da classificação desta pesquisa.

\section{Estudo de caso}

A pesquisa apresentada neste artigo tem como objetivo mostrar a capacidade de aumento de produtividade de uma linha de produção de fluxo contínuo por meio de um estudo de tempos e métodos de todas as operações da linha. Por meio dessa pesquisa analisa-se cálculo do takt time de uma linha de produção, taxa de ocupação dos operadores, como identificar gargalos na produção, macro e micro análises de tempos e propostas de alternativas para eliminar desperdícios.

O estudo de caso divide-se em três etapas principais:

1. Identificação da situação atual;

2. Aumento de produtividade da linha através do estudo de micro movimentos;

3. Aumento da capacidade de produção após adição de dois operadores.

A realização desse estudo de tempos e métodos surgiu como oportunidade para a empresa melhorar a sua produtividade, diminuindo a fadiga e o esforço dos operadores e ainda se adequar às normas do Ministério Público em relação ao tempo de trabalho e o número de pausas obrigatórias por horas trabalhadas. Assim, além dos pontos já citados, também será mostrada a

Tabela 3. Caracterização da pesquisa.

\begin{tabular}{cc}
\hline A pesquisa quanto & Classificação do procedimento metodológico \\
\hline aos procedimentos técnicos & estudo de caso \\
aos objetivos & Exploratória \\
à natureza & Aplicada \\
à abordagem & qualitativa e quantitativa \\
\hline
\end{tabular}

Fonte: Autoria própria (2015). 
mudança no cronograma de produção com a adição de novas pausas durante a jornada de trabalho e o modo de como foi realizada a coleta de dados em cada posto.

\subsection{Processo de fabricação de lentes orgânicas}

Para a produção de lentes orgânicas são necessários: duas fôrmas (uma côncava e outra convexa), um clipe, uma junta plástica e o monômero. A linha de montagem de lentes orgânicas trabalha sobre o sistema de produção puxado e contínuo, com um método de trabalho padronizado para cada uma de suas operações. A linha opera com dois lados, cada um com sua respectiva esteira, com postos duplicados. Possui ao todo 22 funcionários que são distribuídos pelas suas nove operações:

1. Declipagem - O operador retira uma bandeja de uma estrutura metálica localizada dentro de uma das estufas do processo, posiciona-a sobre sua mesa, retira o clipe da fôrma e a coloca sobre a esteira. Ao retirar o clipe da fôrma, ele o coloca em um suporte localizado acima de sua mesa, quando o suporte enche, o operador leva-o ao posto de clipagem e o esvazia, trazendo o suporte vazio novamente ao seu posto de trabalho. Esse posto possui dois operadores, cada um trabalhando em uma esteira da linha;

2. Máquina retiradora de juntas - Esse posto é composto apenas por uma máquina automática. Esta é responsável por retirar a junta plástica da fôrma que o operador colocou na esteira. Há duas máquinas para retirar as juntas, cada uma localizada em uma esteira da linha;

3. Escovagem - Neste posto, o operador recebe a fôrma já sem a junta plástica, segura quatro fôrmas de uma vez e, utilizando uma escova simples, escova-as para retirar o excesso de monômero que pode ter vazado. Após a escovagem, o operador posiciona as fôrmas novamente na esteira;

4. Alimentação de juntas - O operador consulta a programação de lentes que vai passar pela linha, verifica a referência do produto e abastece a linha com uma junta nova, ao lado da respectiva fôrma;

5. Montagem - Esse posto é marcado pela retirada da lente da fôrma. $\mathrm{O}$ operador retira a fôrma e a junta, limpa a junta com ar comprimido, retira a lente de dentro da fôrma, inspeciona a lente colocando-a contra uma lâmpada de inspeção para verificar sua gravação. Se for identificada como mistura de produto, ela é separada, se não, é recolocada na esteira. Após isso, encaixa a junta na fôrma da qual retirou a lente e a coloca no processo novamente. Composto por quatro operadores, duas em cada esteira da linha de montagem;

6. Inspeção - A inspeção ocorre em $100 \%$ das lentes do processo. O operador retira a lente da esteira que está passando na frente dele naquele momento, coloca-a contra a luz de inspeção localizada a sua frente e vê se o produto está conforme ou não. Caso esteja conforme, o operador coloca-a de volta em uma segunda esteira posicionada ao lado da esteira por onde as lentes e fôrmas chegaram. Caso não esteja conforme, o operador retira a lente do processo e registra no sistema o tipo de defeito. A esteira das fôrmas segue para o posto de clipagem, enquanto a esteira das lentes segue para o posto de organização. O posto de inspeção é composto de dois operadores, cada um responsável por inspecionar um lado da linha;

7. Clipagem-A operação consiste em recolocar o clipe retirado das fôrmas de volta nas mesmas. O operador retira a fôrma da esteira, recoloca o clipe e a põe de volta na esteira;

8. Enchimento-Após a fôrma ter de volta a junta plástica e o clipe, o operador recebe a mesma e a posiciona na máquina de enchimento, onde é injetado monômero. O operador coloca a fôrma em uma bandeja e quando esta estiver completa, volta para as estufas de água. Há duas máquinas de enchimento em cada lado da linha;

9. Organização de lentes - No posto de organização de lentes, o operador recolhe as lentes do processo, verifica se há mistura de produtos, registra no sistema a quantidade de cada grupo e organiza as lentes em bandejas ou cestos.

Abaixo, a Figura 1 é uma representação esquemática em formato de fluxograma da linha com todas as operações descritas acima.

\subsection{Coleta de dados}

Descritas as operações que compõem o processo de fabricação de lentes orgânicas, o passo seguinte é a coleta de dados, onde será feita a cronometragem dos ciclos de cada tarefa e a determinação dos tempos médios, tempos normais e tempos padrões. 


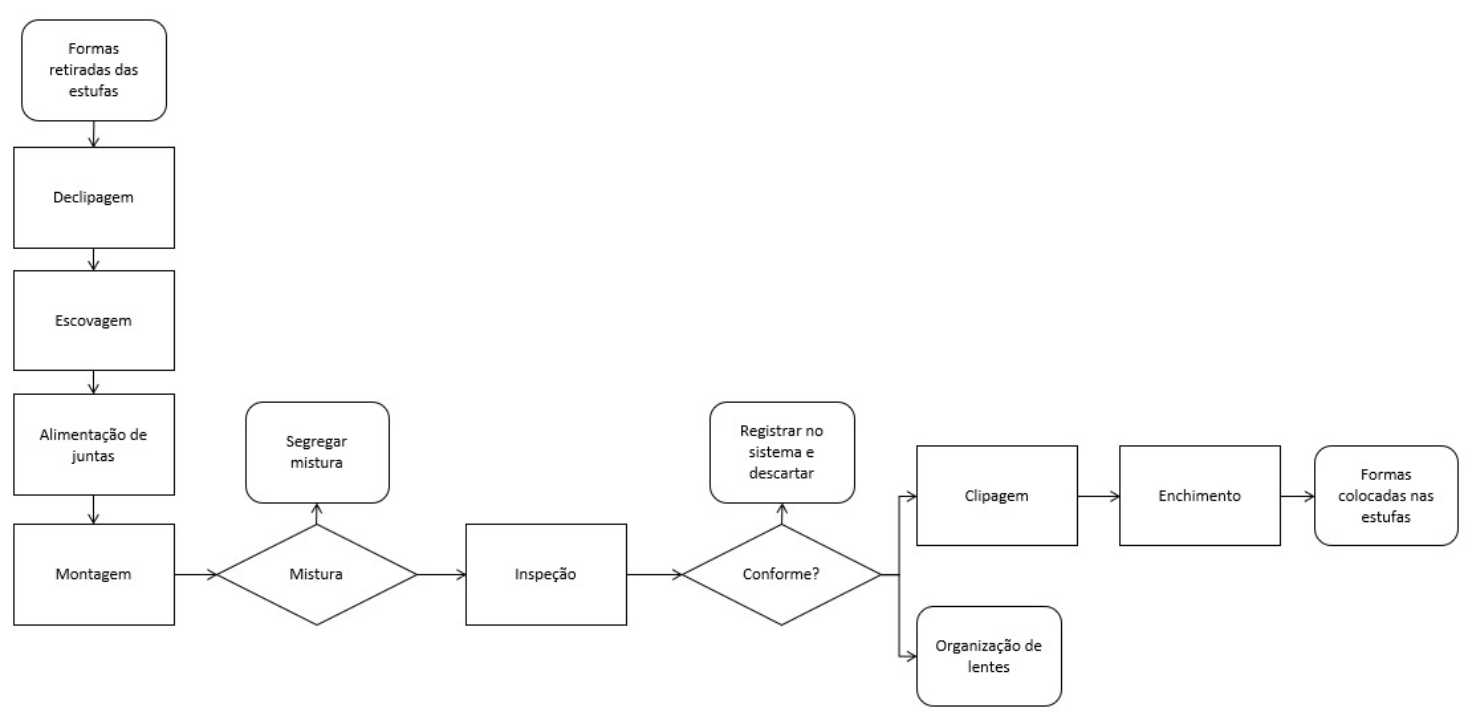

Figura 1. Fluxograma da linha de lentes orgânicas. Fonte: Autoria própria (2016).

Calculado os tempos, monta-se uma tabela com os dados levando em consideração o fator de tolerância e o fator de ritmo. Além das medições de tempos, também coletam-se informações sobre demanda de produção de cada turno, número de pausas por turno e sua duração.

A cronoanálise foi realizada por meio do uso de uma câmera filmadora. É importante ressaltar a preferência da utilização de uma câmera em relação ao cronômetro, pois através da primeira a análise do tempo é mais precisa, uma vez que é possível medir o tempo de acordo com o movimento do operador. Enquanto que na utilização do segundo equipamento, observa-se somente a operação durante o momento em que capta o tempo, além da possibilidade maior de erros na operação do cronômetro e o intervalo de tempo perdido entre o apertar do botão e o término da operação.

As filmagens foram ajustadas para que um segundo de gravação fosse composto de 30 frames, tornando assim a análise mais detalhada. A análise de cada ciclo foi realizada da seguinte maneira: criou-se um quadro com campos para preencher a contagem de frames quando a atividade iniciava e quando a atividade terminava, a subtração é dividida por 30, dando a informação final em segundos. No quadro, também identifica-se qual atividade agrega valor ou não ao produto. Inicialmente, foram filmados sete ciclos de cada operação, mas utilizou-se apenas cinco de cada, pois, normalmente, descarta-se uma ou duas medições que possam conter um elemento estranho na operação. Abaixo o Quadro 1 mostra o modelo utilizado.

Através de documentos de programação, entrevistas e reuniões com os responsáveis pela linha de produção de lentes orgânicas, foi identificado que possui dois turnos com uma demanda de 9700 lentes. O cronograma dos operadores também foi coletado e confirmado na prática o tempo trabalhado pelos operadores.

\subsubsection{Determinação do número de ciclos}

Após a cronometragem das operações, foi calculado o número de ciclos realmente necessários para a realização do estudo de tempos e métodos utilizando a Equação 1, adaptada de Martins \& Laugeni (2006):

$$
N=\left(\frac{z X R}{\operatorname{Er} X d 2 X \bar{x}}\right)
$$

onde: $\mathrm{N}$ = número de ciclos a serem cronometrados; $\mathrm{Z}=$ coeficiente de distribuição normal para uma probabilidade determinada; $\mathrm{R}$ = amplitude da amostra; $\mathrm{Er}=$ erro relativo da medida; $\mathrm{d} 2=$ coeficiente em função do número de cronometragens realizadas preliminarmente; $\bar{x}=$ média dos valores das observações.

Para cada operação foram calculadas a média e amplitude e, a seguir, calculou-se o número de ciclos a serem cronometrados $(\mathrm{N})$ considerando um intervalo de confiança de $95 \%(z=1,65)$ e erro relativo de $5 \%$, devido a alta precisão que as cronometragens pelo uso da filmadora possibilita. Foi utilizado o coeficiente em função do número de cronometragens iniciais como 2,326 (cinco amostras), a média e a amplitude de cada operação foi calculada e está disposta no Quadro 2 abaixo.

\subsubsection{Cálculo do tempo normal e tempo padrão}

Para o cálculo do tempo normal de cada atividade, faz-se necessário primeiro a determinação do fator de ritmo (V). O fator ritmo foi definido para cada 
Quadro 1. Modelo de cronometragem de operações.

\begin{tabular}{|c|c|c|c|c|c|}
\hline F/S & Análise de tempo de ciclo & Valor & \multicolumn{3}{|c|}{ Ciclo 1 } \\
\hline $\mathbf{3 0}$ & Nome do vídeo: & $\begin{array}{c}\text { VA: } 1 \\
\text { NVA: }\end{array}$ & Primeiro & Último & Frames \\
\hline 1 & Operação 1 & 0 & $\mathrm{x} 1$ & $\mathrm{y} 1$ & $\mathrm{y} 1-\mathrm{x} 1$ \\
\hline 2 & Operação 2 & 0 & $\mathrm{x} 2$ & $\mathrm{y} 2$ & $\mathrm{y} 2-\mathrm{x} 2$ \\
\hline 3 & Operação 3 & 0 & $\mathrm{x} 3$ & $\mathrm{y} 3$ & $\mathrm{y} 3-\mathrm{x} 3$ \\
\hline 4 & Operação 4 & 0 & $\mathrm{x} 5$ & $\mathrm{y} 4$ & $\mathrm{y} 4-\mathrm{x} 4$ \\
\hline 5 & Operação 5 & 1 & $\mathrm{x} 6$ & $\mathrm{y} 6$ & $\mathrm{y} 5-\mathrm{x} 5$ \\
\hline 6 & Operação 6 & 0 & $\mathrm{x} 7$ & $\mathrm{x} 8$ & $\mathrm{y} 6-\mathrm{x} 6$ \\
\hline 7 & Operação 7 & 1 & $\mathrm{x} 9$ & $\mathrm{y} 9$ & $\mathrm{y} 7-\mathrm{x} 7$ \\
\hline 8 & Operação 8 & 0 & $\mathrm{x} 10$ & $\mathrm{y} 10$ & $\mathrm{y} 9-\mathrm{x} 8$ \\
\hline 9 & Operação 9 & & & $\mathrm{y} 10-\mathrm{x} 10$ \\
\hline 10 & Operação 10 & Total & & & Soma \\
\hline
\end{tabular}

Fonte: Autoria própria (2015)

Quadro 2. Tempos de ciclo por operação.

\begin{tabular}{|c|l|c|c|c|c|c|c|c|c|}
\hline \multicolumn{9}{|c|}{ Análise do tempo de ciclo (em segundos) } \\
\hline \# & \multicolumn{1}{|c|}{ Video: } & Ciclo 1 & Ciclo 2 & Ciclo 3 & Ciclo 4 & Ciclo 5 & Média & R & $\begin{array}{c}\mathbf{n}^{\circ} \text { de ciclos } \\
\text { ideal }\end{array}$ \\
\hline 1 & Declipagem & 1,57 & 1,60 & 1,40 & 1,47 & 1,57 & 1,52 & 0,20 & 5 \\
\hline 2 & Escovagem & 1,70 & 1,99 & 1,81 & 1,97 & 1,90 & 1,87 & 1,17 & 5 \\
\hline 3 & Alimentação de junta & 1,72 & 1,34 & 1,60 & 1,71 & 1,74 & 1,62 & 0,80 & 12 \\
\hline 4 & Montagem & 2,50 & 2,28 & 2,49 & 2,58 & 2,56 & 2,48 & 1,29 & 3 \\
\hline 5 & Inspeção & 1,59 & 1,33 & 1,53 & 1,39 & 1,30 & 1,43 & 0,58 & 8 \\
\hline 6 & Clipagem & 1,25 & 1,58 & 1,50 & 1,68 & 1,58 & 1,52 & 0,83 & 16 \\
\hline 7 & Enchimento & 1,74 & 1,41 & 1,43 & 1,50 & 1,46 & 1,51 & 1,33 & 10 \\
\hline 8 & Organização de lentes & 1,96 & 1,94 & 2,22 & 2,06 & 2,04 & 2,04 & 0,56 & 4 \\
\hline
\end{tabular}

Fonte: Autoria própria (2015).

operação de acordo com as observações do realizador do estudo de tempos e métodos, sendo determinado como o cálculo do tempo normal (TN) no Quadro 3 abaixo.

Após o cálculo do tempo normal, identifica-se o fator de tolerância (FT) de cada operação, baseado no tempo de pausa cedido pela empresa por turno e condições de trabalho (fadiga, condições atmosféricas, habilidade e consistência), para o cálculo do tempo padrão (TP) de cada atividade. Nesse caso, a empresa cede 35 minutos de pausa dentre os 460 minutos trabalhados. É importante afirmar que o ciclo da máquina retiradora de juntas não entra nesse cálculo, uma vez que por se tratar de uma máquina, não possui fator de ritmo nem tolerância, afinal não há fadiga ou as demais circunstâncias consideradas para as outras operações. Assim o tempo de ciclo normal é igual ao ciclo padrão.

O cálculo do fator de tolerância foi realizado conforme a Equação 2, adaptada de Martins \& Laugeni (2006).

$$
F=\left(\frac{1}{1-p}\right)
$$

onde: $\mathrm{FT}=$ Fator de tolerância; $\mathrm{P}=$ Tempo permissivo.
Quadro 3. Cálculo do tempo normal das operações.

\begin{tabular}{|c|l|c|c|c|}
\hline \multicolumn{5}{|c|}{ Análise do tempo de ciclo (em segundos) } \\
\hline \# & \multicolumn{1}{|c|}{ Video: } & Média & V & TN \\
\hline 1 & Declipagem & 1,52 & 0,01 & 1,54 \\
\hline 2 & Escovagem & 1,87 & 0,06 & 1,98 \\
\hline 3 & Alimentação de junta & 1,57 & 0,05 & 1,65 \\
\hline 4 & Montagem & 2,42 & 0,04 & 2,52 \\
\hline 5 & Inspeção & 1,46 & 0,18 & 1,72 \\
\hline 6 & Clipagem & 1,55 & 0,03 & 1,60 \\
\hline 7 & Enchimento & 1,54 & 0,05 & 1,62 \\
\hline 8 & Organização de lentes & 2,05 & 0,04 & 2,13 \\
\hline
\end{tabular}

Fonte: Autoria própria (2015).

Abaixo o Quadro 4 com o valor de fator de tolerância calculado para cada uma das operações da linha.

Determinado o fator de tolerância para cada operação, os mesmos são multiplicados aos respectivos tempos normais a fim de se obter o tempo padrão necessário para realização de cada atividade como demonstrado no Quadro 5.

\subsection{Situação anterior}

A partir das informações sobre demanda e duração do turno, foi possível calcular o takt time da linha por meio da Equação 3 e montar um diagrama com 
os tempos dos operadores relacionando as horas de trabalho com os tempos de pausa verificado na Figura 2. Os operadores trabalham cerca de sete horas e quarenta minutos por turno, possuem uma hora de almoço e 35 minutos divididos em ginástica (cinco minutos), reunião (dez minutos) e dois intervalos para necessidades pessoais (dez minutos cada).

$$
\text { Takt time }=\frac{\text { tempotrabalhado }}{\text { demanda }}=2,85
$$

Com o resultado do takt time é possível montar um gráfico com o tempo padrão de cada posto e verificar a situação da produção no momento do estudo de acordo com a Figura 3 abaixo.

O gráfico apresenta os tempos de todas as operações da linha estudada, nota-se que todos os ciclos estão de acordo com o takt time necessário para que se atinja a demanda determinada pelos turnos de produção.
Isso significa que a produção de 9700 lentes deve ser alcançada desde que não haja imprevistos, uma vez que com o tempo de ciclo máximo de 2,80 lentes por segundo, é possível produzir um total de 9857 lentes em um turno.

\subsection{Situação proposta}

A proposta da gerência, para melhorar a fadiga e diminuir o esforço dos operadores durante a jornada de trabalho, era que houvesse intervalos de cinco minutos para cada uma hora do turno de produção. Sem eliminar o intervalo do almoço para não descumprir o artigo 70 da CLT, permanecendo com o tempo de cinco minutos para ginástica $\mathrm{e}$ a reunião diária aconteceria em uma das pausas. Essa situação aumentaria a duração de intervalos de 35 minutos para 40 minutos, reduziria o takt time da linha de 2,85 para 2,81 peças por segundo e a

Quadro 4. Cálculo do fator de tolerância das operações.

\begin{tabular}{|c|l|c|c|c|c|c|}
\hline \multicolumn{7}{|c|}{ Análise do tempo de ciclo (em segundos) } \\
\hline$\#$ & \multicolumn{1}{|c|}{ Video: } & Média & V & TN & P & FT \\
\hline 1 & Declipagem & 1,52 & 0,01 & 1,54 & $8 \%$ & 1,091 \\
\hline 2 & Escovagem & 1,87 & 0,06 & 1,98 & $6 \%$ & 1,065 \\
\hline 3 & Alimentação de junta & 1,57 & 0,05 & 1,65 & $8 \%$ & 1,089 \\
\hline 4 & Montagem & 2,42 & 0,04 & 2,52 & $7 \%$ & 1,076 \\
\hline 5 & Inspeção & 1,46 & 0,18 & 1,72 & $8 \%$ & 1,082 \\
\hline 6 & Clipagem & 1,55 & 0,03 & 1,6 & $8 \%$ & 1,087 \\
\hline 7 & Enchimento & 1,54 & 0,05 & 1,62 & $7 \%$ & 1,078 \\
\hline 8 & Organização de lentes & 2,05 & 0,04 & 2,13 & $5 \%$ & 1,058 \\
\hline
\end{tabular}

Fonte: Autoria própria (2015).

Quadro 5. Cálculo do tempo padrão das operações.

\begin{tabular}{|c|l|c|c|c|c|c|}
\hline \multicolumn{7}{|c|}{ Análise do tempo de ciclo (em segundos) } \\
\hline$\#$ & \multicolumn{1}{|c|}{ Video: } & Média & V & TN & FT & TP \\
\hline 1 & Declipagem & 1,52 & 0,01 & 1,54 & 1,091 & 1,67 \\
\hline 2 & Escovagem & 1,87 & 0,06 & 1,98 & 1,065 & 2,11 \\
\hline 3 & Alimentação de junta & 1,57 & 0,05 & 1,65 & 1,089 & 1,80 \\
\hline 4 & Montagem & 2,42 & 0,04 & 2,52 & 1,076 & 2,71 \\
\hline 5 & Inspeção & 1,46 & 0,18 & 1,72 & 1,082 & 1,86 \\
\hline 6 & Clipagem & 1,55 & 0,03 & 1,60 & 1,087 & 1,74 \\
\hline 7 & Enchimento & 1,54 & 0,05 & 1,62 & 1,078 & 1,74 \\
\hline 8 & Organização de lentes & 2,05 & 0,04 & 2,13 & 1,058 & 2,26 \\
\hline
\end{tabular}

Fonte: Autoria própria (2015).

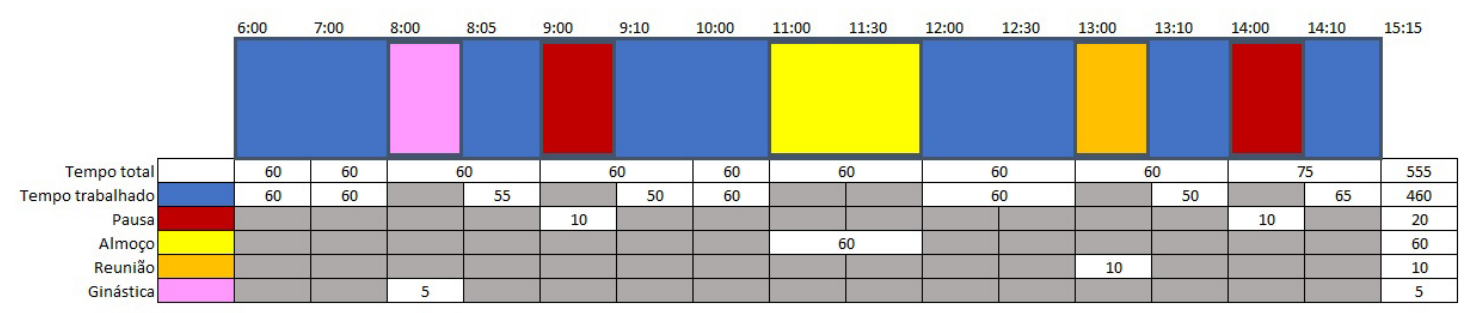

Figure 2. Cronograma da linha de lentes orgânicas. Fonte: Autoria própria (2015). 
capacidade máxima de produção passaria a ser de 9750 lentes por turno. Assim, ainda seria possível atingir a demanda de produção durante o período de trabalho normal, desde que não ocorresse qualquer imprevisto durante o turno.

Adotou-se por cautela intervalos com duração de dez minutos para cada uma hora do turno de produção, uma vez que podem ocorrer atrasos na volta de tais intervalos por diversos motivos. A adaptação da proposta feita pela gerência aumenta o tempo total de intervalos para 70 minutos, divididos entre sete pausas de dez minutos (uma para reunião diária) e uma de cinco minutos para a realização da ginástica laboral. A medida diminui ainda mais o takt time da linha, passando de 2,85 para 2,65 como pode ser visto no gráfico da Figura 4 e no diagrama da Figura 5.

Por meio do gráfico, nota-se que os ciclos das operações de retirar as juntas das fôrmas e da montagem ultrapassam o takt time da linha. A tarefa de retirar juntas é realizada por uma máquina eletromecânica que possui ciclo ajustável, sendo assim, para reduzir o tempo de operação, basta modificar as configurações da máquina utilizando seu software. Entretanto, para reduzir o tempo de montagem, torna-se necessário realizar o estudo de movimentos do operador, identificando atividades que não agregam valor ao produto e/ou desperdícios, e encontrar alternativas para minimizá-las e/ou eliminá-las.

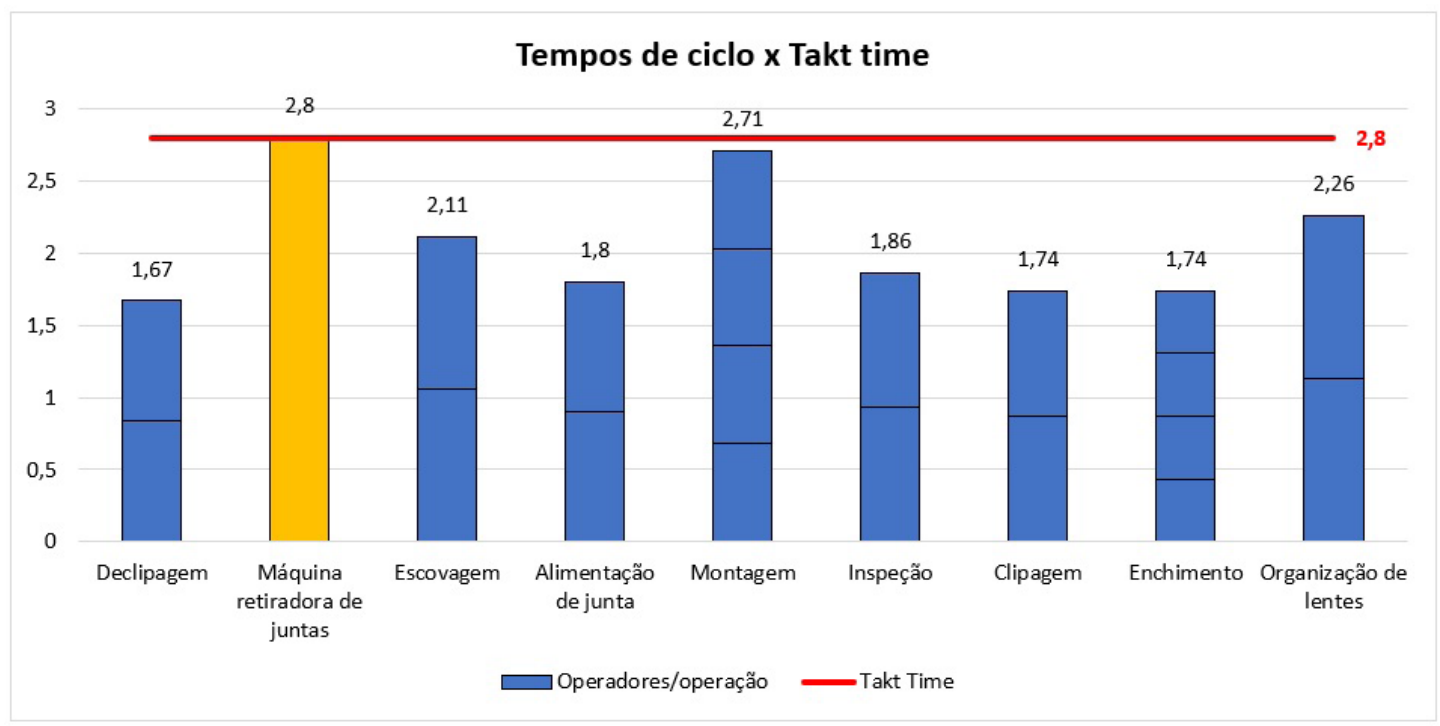

Figura 3. Gráfico de equilíbrio de operação. Fonte: Autoria própria (2015).

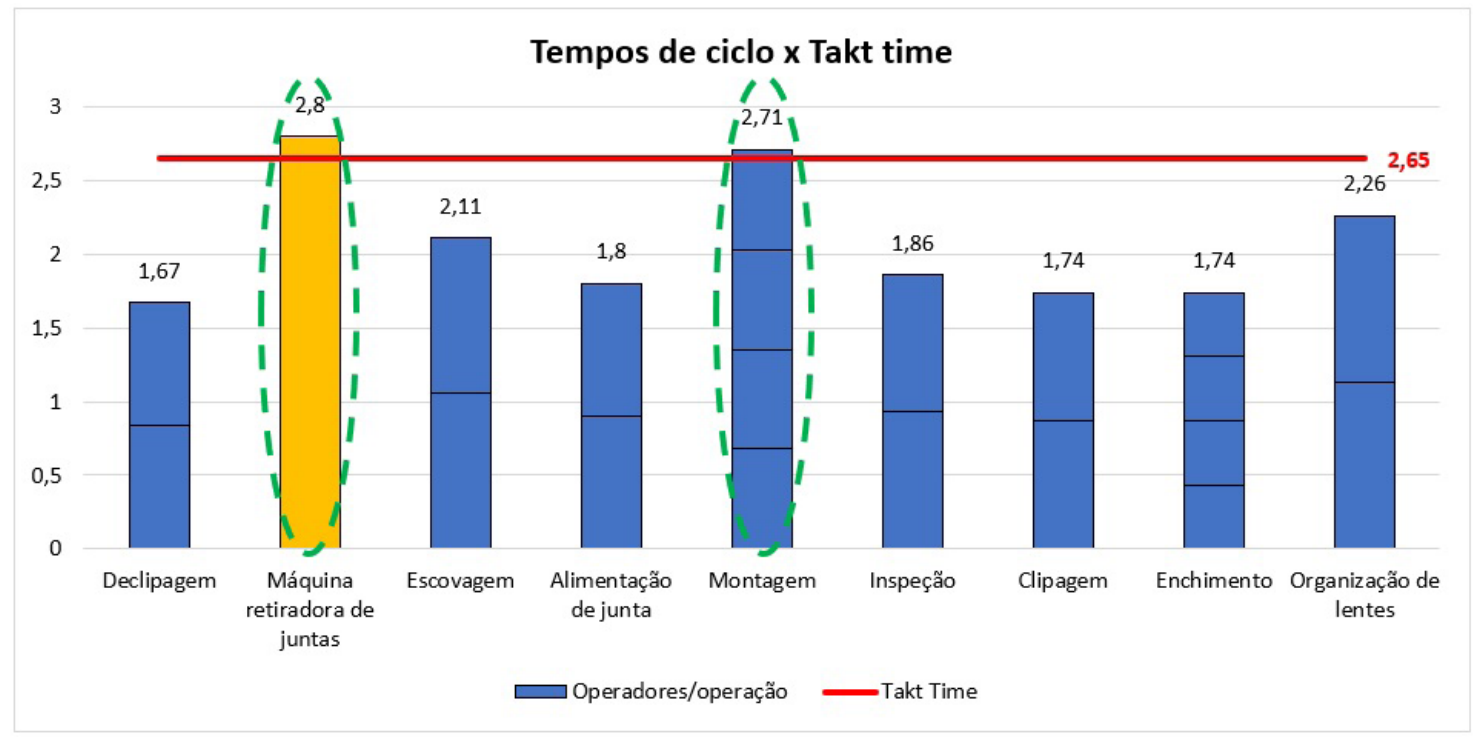

Figura 4. Gráfico de equilíbrio de operação após redução do takt time. Fonte: Autoria própria (2015). 


\subsection{Estudo dos micro movimentos}

O estudo de movimentos da operação de montagem foi realizado utilizando a filmadora e tabela informada na seção 4.1 deste artigo. Foram utilizados três vídeos, conforme foi indicado pela fórmula do número de ciclos ideal a serem cronometrados já calculada anteriormente, e foi analisado cada micro movimento do operador durante a tarefa. Os dados foram colocados no Quadro 6 abaixo.

Na tabela de medições, é computada a média de frames dos três vídeos cronometrados, tempo médio por operadora e por peça, e a quantidade de tempo classificado como valor agregado e valor não agregado. É importante ressaltar que os tempos computados não são tempos padrões para a realização da atividade, e sim os tempos retirados das cronometragens realizadas por vídeo. Através da análise, nota-se que apenas três atividades realizadas pelo operador agregam valor ao produto: desmontar a fôrma, montar o lado côncavo da fôrma e montar o lado convexo da fôrma. Isso não significa que os outros podem ser eliminados, apesar de não agregarem valor ao produto, são necessários para o andamento da produção.
Entretanto, duas atividades do operador são destacadas: levantar a lente e inspecionar a lente. Como descrito na seção 4.1 deste artigo, o operador levanta a lente para colocá-la contra a lâmpada de inspeção e identificar misturas. Entretanto, após este posto, há a operação de inspeção, onde o operador inspeciona $100 \%$ das lentes que passam na esteira, em busca de defeitos no produto, e toma ações provenientes dessa atividade. Assim sendo, este inspetor também é capaz de identificar as gravações das lentes e segregar misturas de processo tanto quanto ou mais que o operador da tarefa de montagem, uma vez que a sua tarefa principal é a verificação do produto. A partir desta conclusão, adicionando a segregação do produto ao inspetor quando este encontrar uma mistura, estes dois micro movimentos realizados pelo operador montador são classificados como desperdício. Afinal não agregam valor ao produto e não são necessários para o processo de montagem, devendo ser eliminados conforme pode ser visto no Quadro 7.

Eliminando os desperdícios, o tempo de ciclo da atividade cai de 2,42 para 2,21. Em seguida, calcula-se os tempos normal e padrão para a realização da operação como pode ser visualizado no Quadro 8.

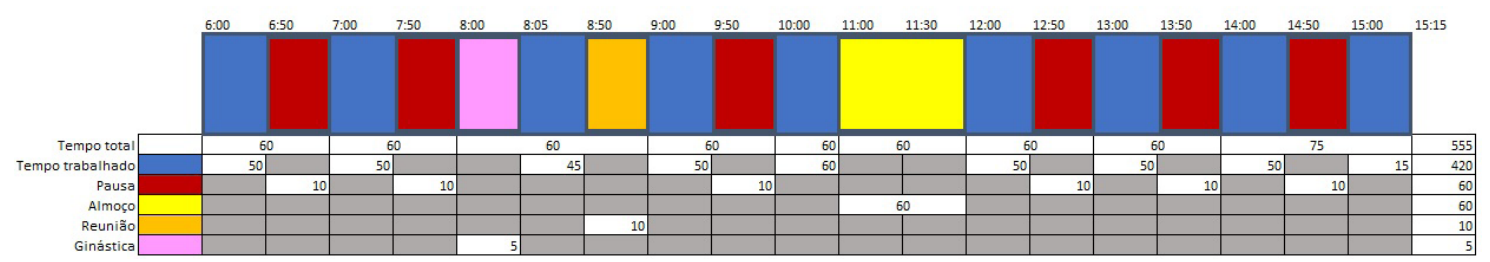

Figura 5. Cronograma da linha após redução do takt time. Fonte: Autoria própria (2015).

Quadro 6. Estudo de micro movimentos da operação de montagem.

\begin{tabular}{|c|c|c|c|c|c|c|c|}
\hline $\mathbf{F} / \mathbf{S}$ & Análise do tempo de ciclo & Valor & \multicolumn{5}{|c|}{ ESTADO ATUAL DO TEMPO DE CICLO } \\
\hline 30 & Video: Montagem & $\begin{array}{l}\text { VA: } 1 \\
\text { NVA: } 0\end{array}$ & $\begin{array}{l}\text { Média de } \\
\text { frames }\end{array}$ & $\begin{array}{c}\text { Tempo } \\
\text { por grupo }\end{array}$ & $\begin{array}{l}\text { Tempo por } \\
\text { unidade }\end{array}$ & VA & NVA \\
\hline 1 & Retirar a fôrma e a junta plástica da esteira & 0 & 13 & 0,11 & 0,43 & & 0,43 \\
\hline 2 & Limpar a junta com ar comprimido & 0 & 18 & 0,15 & 0,60 & & 0,60 \\
\hline 3 & Colocar a junta no suporte & 0 & 11 & 0,09 & 0,37 & & 0,37 \\
\hline 4 & Levantar a fôrma & 0 & 8 & 0,07 & 0,27 & & 0,27 \\
\hline 5 & Limpar a fôrma com ar comprimido & 0 & 22 & 0,18 & 0,73 & & 0,73 \\
\hline 6 & Colocar a fôrma no suporte & 0 & 13 & 0,11 & 0,43 & & 0,43 \\
\hline 7 & Desmontar a fôrma & 1 & 26 & 0,22 & 0,87 & 0,87 & \\
\hline 8 & $\begin{array}{l}\text { Limpar o lado côncavo da fôrma com ar } \\
\text { comprimido }\end{array}$ & 0 & 40 & 0,33 & 1,33 & & 1,33 \\
\hline 9 & Montar o lado côncavo da fôrma & 1 & 38 & 0,32 & 1,27 & 1,27 & \\
\hline 10 & Levantar a lente & 0 & 17 & 0,14 & 0,56 & & 0,56 \\
\hline 11 & Inspecionar a lente & 0 & 8 & 0,07 & 0,28 & & 0,28 \\
\hline 12 & Colocar a lente na esteira & 0 & 10 & 0,08 & 0,33 & & 0,33 \\
\hline 13 & Limpar o lado convexo da fôrma & 0 & 28 & 0,23 & 0,90 & & 0,90 \\
\hline 14 & Montar o lado convexo da fôrma & 1 & 23 & 0,19 & 0,77 & 0,77 & \\
\hline 15 & Colocar a fôrma montada de volta na esteira & 0 & 16 & 0,13 & 0,53 & & 0,53 \\
\hline & Total & & 290 & 2,42 & 9,67 & 2,91 & 6,77 \\
\hline
\end{tabular}

Fonte: Autoria própria (2015). 
Quadro 7. Estudo de micro movimento após eliminação de desperdícios.

\begin{tabular}{|c|l|c|c|c|c|c|}
\hline F/S & \multicolumn{1}{|c|}{ Análise do tempo de ciclo } & \multicolumn{2}{|c|}{ Valor } & \multicolumn{2}{c|}{ ESTADO FUTURO DO TEMPO DE CICLO } \\
\hline $\mathbf{3 0}$ & \multicolumn{1}{|c|}{ Video: Montagem } & $\begin{array}{c}\text { VA: } \\
\text { NVA: }\end{array}$ & $\begin{array}{c}\text { Tempo por } \\
\text { grupo }\end{array}$ & $\begin{array}{c}\text { Tempo por } \\
\text { unidade }\end{array}$ & VA & NVA \\
\hline 1 & Retirar a fôrma e a junta plástica da esteira & 0 & 0,11 & 0,43 & 0,43 \\
\hline 2 & Limpar a junta com ar comprimido & 0 & 0,15 & 0,60 & 0,60 \\
\hline 3 & Colocar a junta no suporte & 0 & 0,09 & 0,37 & 0,37 \\
\hline 4 & Levantar a fôrma & 0 & 0,07 & 0,27 & 0,27 \\
\hline 5 & Limpar a fôrma com ar comprimido & 0 & 0,18 & 0,73 & 0,73 \\
\hline 6 & Colocar a fôrma no suporte & 0 & 0,11 & 0,43 & 0,43 \\
\hline 7 & Desmontar a fôrma & 1 & 0,22 & 0,87 & 0,87 & \\
\hline 8 & Limpar o lado côncavo da fôrma & 0 & 0,33 & 1,33 & 1,33 \\
\hline 9 & Montar o lado côncavo da fôrma & 1 & 0,32 & 1,27 & 1,27 & \\
\hline 10 & Levantar a lente & 0 & 0,00 & & & \\
\hline 11 & Inspecionar a lente & 0 & 0,00 & & \\
\hline 12 & Colocar a lente na esteira & 0 & 0,08 & 0,33 & \\
\hline 13 & Limpar o lado convexo da fôrma & 0 & 0,23 & 0,90 & \\
\hline 14 & Montar o lado convexo da fôrma & 1 & 0,19 & 0,77 & 0,77 & \\
\hline 15 & Colocar a fôrma montada de volta na esteira & 0 & 0,13 & 0,53 & \\
\hline & Total & & $\mathbf{2 , 2 1}$ & $\mathbf{8 , 8 3}$ & 2,91 & 5,93 \\
\hline
\end{tabular}

Fonte: Autoria própria (2015).

Quadro 8. Cálculo dos tempos normal e padrão após eliminação de desperdícios.

\begin{tabular}{|c|l|c|c|c|c|c|}
\hline \multicolumn{7}{|c|}{ Análise do tempo de ciclo (em segundos) } \\
\hline$\#$ & \multicolumn{1}{|c|}{ Video: } & Média & $\mathbf{V}$ & TN & FT & TP \\
\hline 1 & Declipagem & 1,52 & 0,01 & 1,54 & 0,091 & 1,67 \\
\hline 2 & Escovagem & 1,87 & 0,06 & 1,98 & 0,065 & 2,11 \\
\hline 3 & Alimentação de junta & 1,57 & 0,05 & 1,65 & 0,089 & 1,80 \\
\hline $\mathbf{4}$ & Montagem & $\mathbf{2 , 2 1}$ & $\mathbf{0 , 0 4}$ & $\mathbf{2 , 3 0}$ & $\mathbf{0 , 0 7 6}$ & $\mathbf{2 , 4 7}$ \\
\hline 5 & Inspeção & 1,46 & 0,18 & 1,72 & 0,082 & 1,86 \\
\hline 6 & Clipagem & 1,55 & 0,03 & 1,60 & 0,087 & 1,74 \\
\hline 7 & Enchimento & 1,54 & 0,05 & 1,62 & 0,078 & 1,74 \\
\hline 8 & Organização de lentes & 2,05 & 0,04 & 2,13 & 0,058 & 2,26 \\
\hline
\end{tabular}

Fonte: Autoria própria (2015).

Com o tempo de ciclo da máquina retiradora de juntas ajustado para o mesmo valor da montagem (2,47 segundos), a linha fica com uma capacidade de produção de 10202 lentes por turno.

\subsection{Resultados}

O estudo de tempos e movimentos das operações permitiu a redistribuição de pausas durante os turnos de produção da linha de lentes orgânicas, diminuindo a fadiga dos operadores e aumentando a capacidade de produção da linha, mesmo com a redução do takt time. Por meio da análise do gráfico da Figura 6, nota-se que a linha ficou mais balanceada após o ajuste do tempo de ciclo da máquina retiradora de juntas e a eliminação da inspeção de lentes durante a montagem.

Entretanto, mesmo após o estudo de tempos e métodos, o maior tempo de ciclo continua sendo da operação de montagem. Porém, ainda é possível diminuir sua duração realizando novamente a análise de micro movimentos e descobrindo modos de evitar desperdícios ou diminuir tempos de atividades não agregadoras de valor. Outra possibilidade viável é configurar a linha para que se tenha três montadores de cada lado, assim, o tempo de montagem seria dividido por seis e não por quatro como colocado no Quadro 9. Em seguida, o próximo passo seria calcular novamente o tempo normal e o tempo padrão da operação e construir o Quadro 10 e o novo gráfico na Figura 7 de tempos de ciclo.

Adicionando mais uma operadora de montagem em cada lado da linha, a operação deixa de ser o gargalo para ser o segundo tempo mais baixo, deixando a linha ainda mais balanceada. A capacidade de produção passa a ser de 11004 lentes por turno. A demanda de lentes pode ser aumentada sem causar sobrecarga aos operadores caso a gerência de produção ache necessário. Apesar dos resultados positivos, se 


\section{Tempos de ciclo $\mathrm{x}$ Takt time}

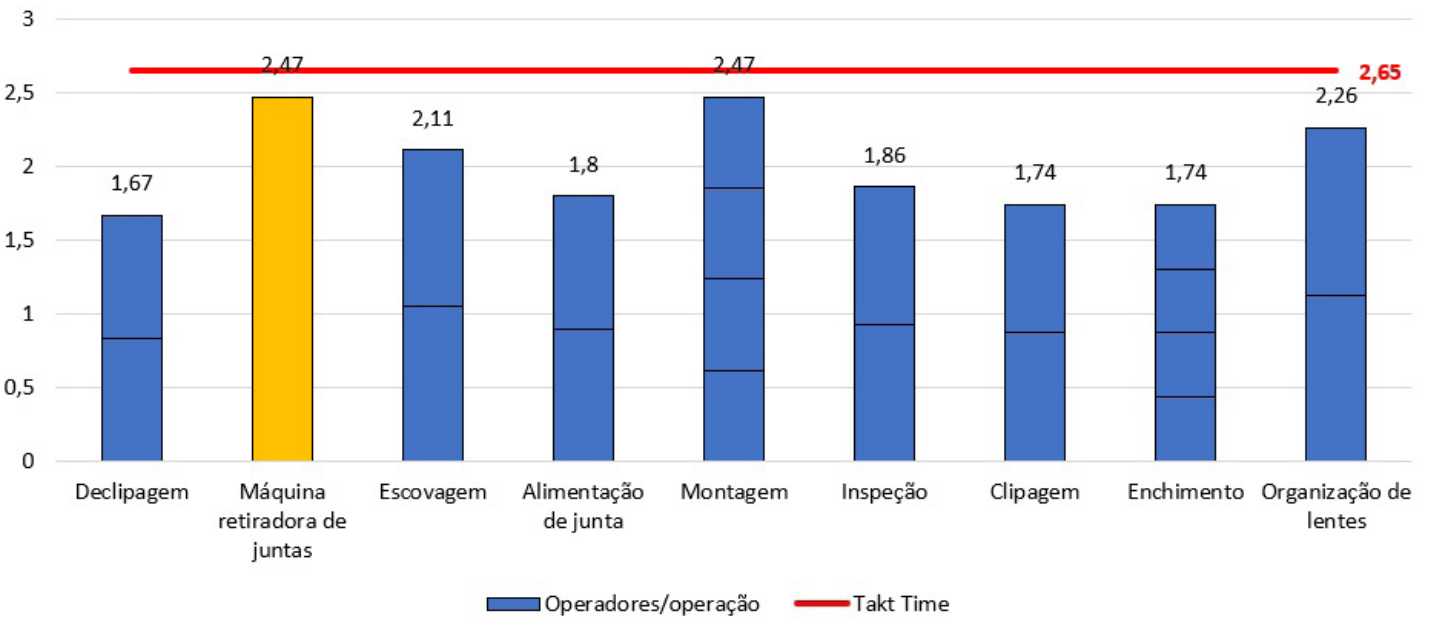

Figura 6. Gráfico de equilíbrio das operações após eliminação de desperdícios. Fonte: Autoria própria (2015).

Quadro 9. Estudo de micro movimentos após a adição de dois operadores.

\begin{tabular}{|c|l|c|c|c|c|c|}
\hline F/S & \multicolumn{1}{|c|}{ Análise do tempo de ciclo } & \multicolumn{2}{|c|}{ Valor } & \multicolumn{2}{|c|}{ ESTADO FUTUR DO TEMPO DE CICLO } \\
\hline $\mathbf{3 0}$ & \multicolumn{1}{|c|}{ Video: Montagem } & $\begin{array}{c}\text { VA: } \mathbf{1} \\
\text { NVA: } \mathbf{0}\end{array}$ & $\begin{array}{c}\text { Tempo por } \\
\text { grupo }\end{array}$ & $\begin{array}{c}\text { Tempo por } \\
\text { unidade }\end{array}$ & VA & NVA \\
\hline 1 & Retirar a fôrma e a junta plástica da esteira & 0 & 0,07 & 0,43 & & 0,43 \\
\hline 2 & Limpar a junta com ar comprimido & 0 & 0,10 & 0,60 & & 0,60 \\
\hline 3 & Colocar a junta no suporte & 0 & 0,06 & 0,37 & & 0,37 \\
\hline 4 & Levantar a fôrma & 0 & 0,04 & 0,27 & & 0,27 \\
\hline 5 & Limpar a fôrma com ar comprimido & 0 & 0,12 & 0,73 & & 0,73 \\
\hline 6 & Colocar a fôrma no suporte & 0 & 0,07 & 0,43 & & 0,43 \\
\hline 7 & Desmontar a fôrma & 0 & 0,14 & 0,87 & 0,87 & \\
\hline 8 & Limpar o lado côncavo da fôrma & 1 & 0,21 & 1,33 & & 1,33 \\
\hline 9 & Montar o lado côncavo da fôrma & 0 & 0,00 & & & \\
\hline 10 & Levantar a lente & 0 & 0,00 & & & \\
\hline 11 & Inspecionar a lente & 0 & 0,06 & 0,33 & & 0,33 \\
\hline 12 & Colocar a lente na esteira & 1 & 0,15 & 0,90 & & 0,90 \\
\hline 13 & Limpar o lado convexo da fôrma & 0 & 0,09 & 0,53 & & 0,53 \\
\hline 14 & Montar o lado convexo da fôrma & & $\mathbf{1 , 4 7}$ & $\mathbf{8 , 8 3}$ & 2,91 & 5,93 \\
\hline 15 & Colocar a fôrma montada de volta na esteira & & & & \\
\hline & Total CT & & & 0,77 & 0,77 & \\
\hline
\end{tabular}

Fonte: Autoria própria (2015).

Quadro 10. Cálculo de tempos normais e padrão após adição de dois operadores.

\begin{tabular}{|c|l|c|c|c|c|c|}
\hline \multicolumn{7}{|c|}{ Análise do tempo de ciclo (em segundos) } \\
\hline$\#$ & \multicolumn{1}{|c|}{ Video: } & Média & $\mathbf{V}$ & TN & FT & TP \\
\hline 1 & Declipagem & 1,52 & 0,01 & 1,54 & 0,091 & 1,67 \\
\hline 2 & Escovagem & 1,87 & 0,06 & 1,98 & 0,065 & 2,11 \\
\hline 3 & Alimentação de junta & 1,57 & 0,05 & 1,65 & 0,089 & 1,80 \\
\hline $\mathbf{4}$ & Montagem & $\mathbf{1 , 4 7}$ & $\mathbf{0 , 0 4}$ & $\mathbf{1 , 5 3}$ & $\mathbf{0 , 0 7 6}$ & $\mathbf{1 , 6 4}$ \\
\hline 5 & Inspeção & 1,46 & 0,18 & 1,72 & 0,082 & 1,86 \\
\hline 6 & Clipagem & 1,55 & 0,03 & 1,60 & 0,087 & 1,74 \\
\hline 7 & Enchimento & 1,54 & 0,05 & 1,62 & 0,078 & 1,74 \\
\hline 8 & Organização de lentes & 2,05 & 0,04 & 2,13 & 0,058 & 2,26 \\
\hline
\end{tabular}

Fonte: Autoria própria (2015). 


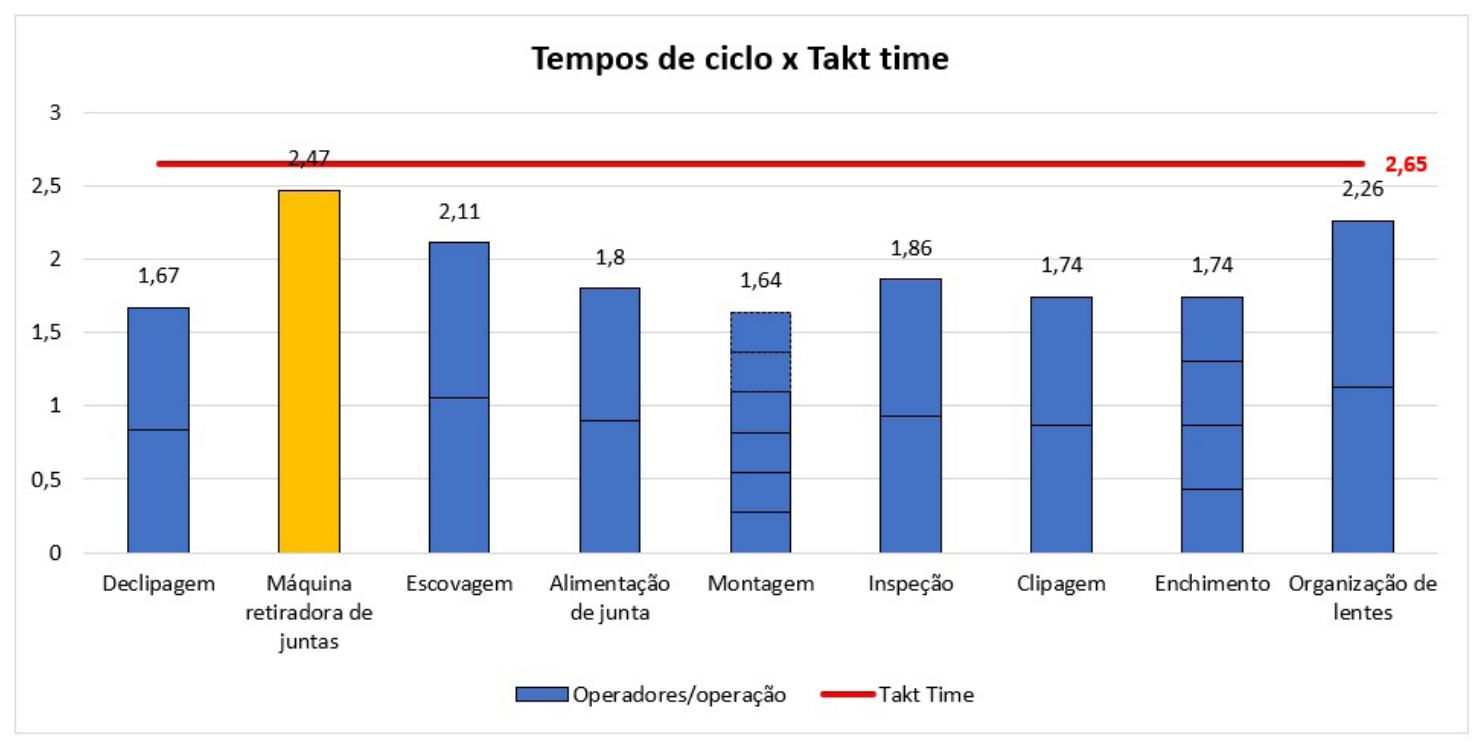

Figura 7. Gráfico de equilíbrio de operações após adição de dois operadores. Fonte: Autoria própria (2015).

ainda houver intenção de aumentar a capacidade de produção da linha, basta repetir os mesmos passos para operação de organização de lentes.

\section{Considerações finais}

O estudo de tempos e métodos permite o desenvolvimento da melhoria contínua dentro das organizações. Técnica que surgiu junto com a filosofia Lean Manufacturing (produção enxuta), no Sistema Toyota $^{\circledR}$ de Produção, possibilita a otimização de processos produtivos, garantindo flexibilidade, menores custos, e mais rapidez na entrega de produtos ao cliente.

Este artigo aborda um estudo de caso realizado em uma fábrica de lentes, onde a utilização do estudo de tempos e métodos possibilitou o aumento da capacidade produtiva com a redução do takt time da linha e dos tempos de ciclo de cada operação. $\mathrm{O}$ artigo possui três etapas principais: a análise da situação antes do estudo, a redução através do estudo de micro movimentos e o resultado após acrescentar dois operadores na operação gargalo da linha.

A situação estudada mostrava que os operadores possuíam apenas três intervalos durante todo o turno de trabalho, um ainda utilizado para reunião diária ao invés de necessidades pessoais. O objetivo inicial era adicionar pausas de cinco minutos a cada uma hora de trabalho. Para isso, foram estudados os ciclos de cada operação antes e depois de adicionar as pausas e as condições da linha foram verificadas. Após realizadas as cronoanálises mencionadas, identificou-se duas operações consideradas como gargalos.

A aplicação da técnica de tempos e métodos mostrou-se eficaz, uma vez que utilizada foi possível identificar atividades consideradas não só como não agregadoras de valor, como também consideradas desperdício eliminando-as da linha de produção, diminuindo o gargalo da linha e aumentando a capacidade produtiva.

Por meio do estudo de micro movimentos da operação de montagem, encontrou-se a oportunidade de deixar a linha mais balanceada adicionando dois operadores para esta tarefa. Assim, além de concluir o objetivo de adicionar as pausas durante o turno de trabalho, a linha teve sua capacidade de produção elevada e não mais a operação de montagem como gargalo.

\section{Referências}

Barnes, R. M. (1977). Estudo de movimentos e de tempos: projeto e medida do trabalho. São Paulo: Edgard Blucher.

Contador, J. C. (1998). Gestão de operações: Engenharia de Produção a serviço da modernização da empresa. São Paulo: Edgard Blucher.

Gil, A.C. (2010). Como elaborar projetos de pesquisa (5. ed.). São Paulo: Atlas.

Greef, A. (2012). Lean office: operação, gerenciamento e tecnologias. São Paulo: Atlas.

Houts, L. (2016). Minimizing the seven wastes at Betts Spring Manufacturing. International Journal of Business and Applied Social Science, 2(4), 23-28.

Juran, J. M. (1990). Na liderança pela qualidade. São Paulo: Pioneira.

Llewellyn, S., \& Northcott, D. (2007). The "singular view" in management case studies qualitative research in organizations and management. International Journal, 2(3), 194-207.

Marksberry, P., Rammohan, R., \& Vu, D. (2011). A systems study on standardized work: a Toyota perspective. 
International Journal of Productivity and Quality Management, 7(3), 287-302. http://dx.doi.org/10.1504/ IJPQM.2011.039349.

Martins, P. G., \& Laugeni, F. P. (2006). Administração da produção (2. ed.). São Paulo: Saraiva.

Mayer, P. C., Maciel, A. C., Baggio, D. K., \& Siedenberg, D. R. (2015). Implantação de metodologia de análise do valor agregado em uma indústria metalúrgica de produtos sob encomenda. Gestão da Produção, Operações e Sistemas, 10(1), 177-195.

Paladini, E. (2012). Gestão da qualidade (2. ed.). Rio de Janeiro: ABEPRO.

Sabet-Rasekh, A. (2014). Design of a lean manufacturing system for the production of compliant wind at sparton electronics (Master thesis). Embry-Riddle Aeronautical University, Daytona Beach, Florida.

Souto, M. S. M. L. (2002). Apostila de engenharia de métodos. João Pessoa: Curso de Especialização em Engenharia de Produção, UFPB.
Terence, A. C. F., \& Escrivão-Filho, E. (2006). Abordagem quantitativa, qualitativa e a utilização da pesquisa-ação nos estudos organizacionais. In Anais do XXVI Encontro Nacional de Administração. Fortaleza: ENEGEP. Recuperado em 12 de dezembro de 2015, de http:// www.abepro.org.br/biblioteca/ENEG EP2006_TR54 0368 8017.pdf

Wang, W., Lu, Z., \& Zhu, Q. (2014). The integration of group technology and simulation optimization to solve the flow shop with highly variable cycle time process: a surgery scheduling case study. Mathematical Problems in Engineering, 2014, 1-8. http://dx.doi. org/10.1155/2014/547485.

Werkema, C. (2011). Lean Seis Sigma: introdução às ferramentas do lean manufacturing (2. ed.). Rio de Janeiro: Elsevier.

Werkema, C. (2012). Criando a cultura Seis Sigma (3. ed.). Rio de Janeiro: Elsevier. 